\title{
Original Article \\ Awareness of breast cancer in women of an urban resettlement colony
}

\author{
Somdatta P, Baridalyne N \\ Centre for Community Medicine, AlIMS, New Delhi-110 029, India
}

Correspondence to: Dr Somdatta Patra, E-mail: somdattap@gmail.com

\begin{abstract}
BACKGROUND: Breast cancer accounts for $19-34 \%$ of all cancer cases among women in India. There is a high mortality due to late stage diagnosis as patients usually present at an advanced stage because of lack of awareness and nonexistent breast cancer screening programs. AIM: To determine the awareness about breast cancer among women in an urban resettlement colony in Delhi. SETTINGS AND DESIGN: A community based, cross-sectional study carried out in a resettlement colony in South Delhi. MATERIALS AND METHODS: Semi-structured interview schedule was used to collect information regarding breast cancer. Modified Kuppuswamy scale was used for assessing the socio-economic status. RESULTS AND CONCLUSIONS: A total of 333 women were included. The mean age was 36 years \pm 15.1 and $46 \%$ were illiterate. Only $185(56 \%)$ women were aware of breast cancer; among them, $51 \%$ knew about at least one of the signs /symptoms, $53 \%$ were aware that breast cancer can be detected early, and only $35 \%$ mentioned about risk factors. Thus, awareness about breast cancer is low amongst women in this community. There is a need for awareness generation programs to educate women about breast cancer, propagation of correct messages and promote early detection of breast cancer.
\end{abstract}

Key words: Awareness, breast cancer, India, urban resettlement colony

\section{Introduction}

In India cancer prevalence is estimated around 2.5 million, with over 0.8 million new cases and 0.5 million deaths occurring each year. ${ }^{[1]}$ The common sites for cancer in India are oral cavity, lungs, esophagus and stomach in males and cervix, breast and oral cavity among females. Breast cancer accounts for $19-34 \%$ of all cancer cases among women in India. ${ }^{[2-4]}$ According to $\mathrm{N}$ ational $\mathrm{Cancer}$ Registries and Regional Cancer Centers, it is the commonest cancer amongst women in D elhi, M umbai, Ahmedabad, Kolkata and Trivandrum. ${ }^{[2-6]}$ In all other cancer registries, it is listed as the second most common cancer among women. Moreover, data from national and regional cancer centers from 1984 to 2002 also show that there is an increase in the incidence of breast cancer and found to be gradually overtaking cancer of the cervix.

M ost of the patients seek medical advice when the disease is fairly advanced. Over $70 \%$ of the cases report for diagnostic and treatment services in advanced stages of the disease, resulting in poor survival and high mortality rates. ${ }^{[7]}$ Early Breast Cancer (EBC) constitutes only 30\% of the breast cancer cases seen at different cancer centers in India whereas it constitutes $60-70 \%$ of cases in the developed world. ${ }^{[8]}$ In India the incidence/mortality ratio is 0.48 compared with 0.25 in N orth America. ${ }^{[9]}$ Late diagnosis is a major factor for this high mortality as most patients present in advanced stage of the disease. This is attributed to lack of awareness and non-existent breast cancer screening programs in India. As breast cancer is a topic that is not freely discussed in India because of cultural taboo, there is an urgent need for information and education on awareness of breast cancer and its early detection measures. Keeping in mind that $\mathrm{O}$ ctober is observed worldwide as Breast Cancer Awareness Month, this study was planned in October 2007 to find out the awareness about breast cancer among women in an urban resettlement colony in D elhi.

\section{Materials and Methods}

A cross-sectional community based survey was conducted at $\mathrm{Dr}$ A mbedkar $\mathrm{N}$ agar, $\mathrm{N}$ ew D elhi, which is a resettlement colony. ( $A$ resettlement colony is defined 
as a colony created by removing a group of households from the congested city core or an encroachment in public places and locating them generally in the periphery of the city). The study area is the field practice area of Department of Community M edicine of a Medical College of Delhi. The urban health program of this medical college runs in a resettlement colony in south Delhi, which is around eight kilometers from this medical college. Six blocks in this area have been adopted by this college. Every morning the urban health team consisting of doctors, Public health N urse, pharmacist, Medical Social Worker and laboratory technician, run a mobile clinic and thus provide medical services in this region. Besides, regular home visits are made by multipurpose workers in the assigned blocks. One block out of the six blocks was randomly selected for the study. In order to calculate the sample size, we referred to a study carried out in an urban slum area of Delhi, ${ }^{[10]}$ which reported that $51 \%$ of the participants had some knowledge regarding cancer in general. Therefore, based on this study, as we could not find any data about awareness of breast cancer, we assumed a prevalence of $50 \%$, and an absolute error of $5 \%$, the sample size was calculated to be 400 with power $80 \%$ and confidence level $95 \%$.

The study participants included all women aged 15 years and above, residing in the selected block for the last six months. Data were collected from 0 ctober 2007 to December 2007. The study participants were recruited from the consecutive houses. A pre-tested semistructured interview schedule was administered to collect information regarding various aspects of breast cancer such as early warning signs, risk factors, early detection measures and their source of information. The Modified Kuppuswamy scale ${ }^{[11]}$ was used for assessing the socioeconomic status (SES) of the family [Annexure 1].

\section{Ethical issues}

The objective and study protocol were explained to the study participants and verbal informed consent was obtained. D uring the course of the study, those women who needed any kind of medical treatment were referred to the mobile OPD or to a designated medical college as required.

\section{Analysis of data}

D ata were entered in MS excel and analysis was done using Statistical Package for Social Sciences version 11. Chi-square was applied to test the difference in awareness levels by literacy, socio economic status and age.

150

\section{Results}

A total of 358 women were contacted for the study. Twenty-five women $(6.9 \%)$ refused to participate. Thirty-two houses were found locked and in another eighteen houses no respondents were found. O ut of 333 women who participated in the study one third were in the age group of 21-30 years [Table 1]. The mean age of the study participants was 36 years \pm 15.1 , the range being 16 to 80 years. Forty-six percent of the study participants were illiterate. About one third (34\%) of the population, belonged to the upper-lower socioeconomic status.

\section{Awareness about breast cancer}

O ut of the 333 women interviewed, eighty-eight percent $(n=294)$ were aware of cancer as a disease. However, only about half of women $(n=185)$ were aware of breast cancer. It was seen that the proportion of women who were aware increased as the literacy status increased, and this was statistically significant. Similarly, those who belonged to higher socioeconomic status were more aware about breast cancer as compared to those belonging to a lower SES and this difference was also statistically significant. H owever, we did not find statistically significant association between age and awareness of breast cancer [Table 1].

\section{Knowledge of signs and symptoms}

$O$ ut of 185 participants who were aware of breast cancer as disease, $51 \%(n=95)$ of them mentioned at least one of the signs/symptoms of breast cancer [Table 2]. Though 79 women (42\%) knew that a lump is an early symptom, only $5 \%$ knew that painless lump is a symptom of breast cancer. Forty-one percent $(n=76)$ of them mentioned pain as a symptom. Only 13 women (7\%) mentioned nipple discharge, and another $1.6 \%$ $(n=3)$ mentioned skin changes. Other symptoms identified were fever, itching, weight loss, breast abscess, and presence of breast ulcer.

\section{Knowledge about risk factors}

O nly $35 \%(n=65)$ of the women mentioned any of the risk factors of breast cancer [Table 2]. $\mathrm{N}$ ine women (4.9\%) mentioned advancing age as a risk factor, while $12(6.5 \%)$ believed that risk is more at younger age. Eight percent $(n=15)$ believed that taking oral contraceptive can cause breast cancer irrespective of the duration of intake. Forty-five (24\%) women believed that breast feeding protects against breast cancer while five women thought breast feeding is a risk factor. 0 ther factors that that were mentioned were obesity and excessive intake of fat. Interestingly, $20 \%$ of the participants believed that trauma to the breast while feeding leads to breast cancer. 
Table 1: Awareness of breast cancer as a form of cancer and different socio-demographic characteristics

\begin{tabular}{|c|c|c|c|c|}
\hline Characteristics & $\begin{array}{c}\text { Aware of } \\
\text { Breast } \\
\text { Cancer } \\
\text { No (\%) }\end{array}$ & $\begin{array}{c}\text { Not aware } \\
\text { of Breast } \\
\text { Cancer } \\
\text { No (\%) }\end{array}$ & Total & $P$ value* \\
\hline \multicolumn{5}{|l|}{ Education } \\
\hline Illiterate & $74(49)$ & $78(51)$ & 152 & $p^{\dagger}=0.000$ \\
\hline Primary & $66(53)$ & $59(47)$ & 125 & \\
\hline High school & $27(71)$ & $11(29)$ & 38 & \\
\hline $\begin{array}{l}\text { Higher seconda } \\
\text { and above }\end{array}$ & ry 18 (100) & 0 & 18 & \\
\hline \multicolumn{5}{|c|}{ Socio-economic status } \\
\hline Lower & $22(41)$ & $32(59)$ & 54 & $p^{\ddagger}=0.001$ \\
\hline Upper lower & $55(47)$ & $61(53)$ & 116 & \\
\hline Lower-middle & $55(65)$ & $30(35)$ & 85 & \\
\hline $\begin{array}{l}\text { Upper-middle } \\
\text { and above }\end{array}$ & $53(68)$ & $25(32)$ & 78 & \\
\hline \multicolumn{5}{|l|}{ Age group (yrs) } \\
\hline $16-20$ & $24(45)$ & $30(56)$ & 54 & $p^{\S}=0.13$ \\
\hline $21-30$ & $61(57)$ & $46(43)$ & 107 & \\
\hline $31-40$ & $46(67)$ & $23(33)$ & 69 & \\
\hline $41-50$ & $23(51)$ & $22(49)$ & 45 & \\
\hline $51-60$ & $18(62)$ & $11(38)$ & 29 & \\
\hline$>60$ & $13(45)$ & $16(55)$ & 29 & \\
\hline
\end{tabular}

${ }^{\star} P$ value $<0.05$ is statistically significant; ${ }^{\dagger}$ Pearson Chi-square value 21.387, degrees of freedom (df) 3; ${ }^{*}$ Pearson Chi-square value 15.649, degrees of freedom (df) 3; sPearson Chi-square value 8.452, degrees of freedom (df) 5

\section{Knowledge about early detection methods}

Fifty three percent of the participants $(n=98)$ were aware that breast cancer can be detected early [Table 2]. Almost half of them $(n=96)$ said that it could only be detected by a doctor. Though $11 \%$ women were aware of breast self-examination, and only two of them have ever done breast self-examination. These two women have a history of surgical lump removal. H owever, none of them do it on a regular basis. Five women have had clinical breast examination done when they experienced some pain in the breast. O nly six women knew about early detection by mammography.

\section{Knowledge about preventive measures}

When asked how breast cancer can be prevented seventeen women mentioned regular check-up by a doctor; others said that breast cleanliness, washing nipples regularly, and not wearing underwear (brassier) can prevent breast cancer.
Table 2: Respondents' knowledge of different aspects of breast cancer

\begin{tabular}{lc} 
Response & $\begin{array}{c}\text { Frequency } \\
\text { (\%) } \mathbf{n}=\mathbf{1 8 5}\end{array}$ \\
\hline Early warning signs & \\
\hline $\begin{array}{l}\text { A) Mentioned at least one early } \\
\text { warning sign/ symptom }\end{array}$ & $95(51)$ \\
\hline 1. Breast lump & $79(42)$ \\
\hline 2. Painless lump & $9(4.9)$ \\
\hline 3. Pain in breast & $76(41)$ \\
\hline 4. Breast abscess & $32(17)$ \\
\hline 5. Nipple discharge & $13(7)$ \\
\hline \multicolumn{1}{c}{ 6. Skin changes } & $3(1.6)$ \\
\hline B) Not aware of any early & $90(49)$ \\
warning sign/symptom &
\end{tabular}

Risk factor/ protective factor

A) Mentioned at least one risk factor

\begin{tabular}{lc} 
Risk factors mentioned were: & $65(35)$ \\
\hline 1. Advancing age & $9(4.9)$ \\
\hline 2. Younger age & $12(6.5)$ \\
\hline 3. Multi-parity & $15(8)$ \\
\hline 4. Oral contraceptive pills intake & $15(8)$ \\
\hline 5. Breast feeding & $5(3)$ \\
\hline 6. Tobacco intake & $37(20)$ \\
\hline 7. Obesity & $21(11)$ \\
\hline 8. Thin women & $12(7)$ \\
\hline 9. Trauma to breast while feeding the child & $37(20)$ \\
\hline 10. High dietary fat intake & $2(1)$ \\
\hline B) Not aware of any risk factors & $120(65)$ \\
\hline C) Breast feeding as a protective factor & $45(24)$ \\
\hline
\end{tabular}

\section{Early detection methods}

A) Mentioned at least one early 98 (53) detection method

\begin{tabular}{lc}
\hline 1. Clinical examination by a doctor & $96(52)$ \\
\hline 2. Self breast examination & $21(11)$ \\
\hline 3. Mammography & $6(3)$ \\
\hline B) Not aware of any early detection method & $87(47)$ \\
\hline
\end{tabular}

\section{Preventive measures}

\begin{tabular}{lc}
\hline 1. Regular check up by a doctor & $17(9)$ \\
\hline 2. Others (e.g. breast cleanliness) & $9(4.9)$ \\
\hline 3. Not aware of any preventive measure & $168(91)$ \\
\hline
\end{tabular}

\section{Source of information}

\begin{tabular}{lc}
\hline 1. Television & $80(42)$ \\
\hline 2. Neighbors and relatives & $76(41)$ \\
\hline 3. Hospital staff & $35(19)$ \\
\hline 4. Print material & $16(9)$ \\
\hline 5. Radio & $6(3)$ \\
\hline
\end{tabular}




\section{Source of information}

The television is the most common medium through which women heard about breast cancer [Table 2]. 0 ther sources of knowledge were neighbors and relatives $(41 \%)$, hospital staff $(19 \%)$, print media $(9 \%)$ and radio $(3 \%)$.

\section{Discussion}

Till now there is no established national screening program for breast cancer in the country. In the present study we found that only $56 \%$ of the respondents were aware of breast cancer as a disease. Those who were aware were of higher socio-economic strata or the more educated. It has been shown that women of low SES have a low incidence of breast cancer compared to women of higher SES, but they experience a higher mortality rate, due to higher late stage diagnosis. ${ }^{[12]}$ Reports from other studies also show that educated women are more aware of breast cancer. ${ }^{[13,14]}$ In this study very few women correctly identified early warning signs of breast cancer; especially such sign as a painless lump which is similar to results of studies done in Nigeria. ${ }^{[13,15]}$

K nowledge and awareness of early detection measures of breast cancer such as breast self-examination (BSE) is also low. The findings show that few of the participants knew about BSE as an early detection measure, and hardly very few women practice it. It is established that screening by mammography can substantially reduce mortality from breast cancer, especially in women over the age of 50 years. ${ }^{[16]}$ But this technique is expensive and for this reason difficult to adopt in a country like India as a routine public health measure. A cohort study in Finland ${ }^{[17]}$ and a case-contro| ${ }^{[18]}$ study in Canada suggested BSE to be beneficial (reduction in breast cancer mortality) at all ages. Recently there is a debate on the role of regular self-examination of the breast in preventing breast cancer mortality. ${ }^{[19]} \mathrm{H}$ owever the teaching of BSE can help women to be alert to any abnormal changes in their breasts and seek medical advice immediately. O ne study carried out in Karnataka has suggested that this can be used as a strategy for creating breast health awareness among women, and female health workers can be trained to teach the women to carry out BSE. ${ }^{[20]}$

The World $\mathrm{H}$ ealth O rganization stresses on promoting awareness in the community and encouraging early diagnosis of breast cancer, especially for women aged 40-69 years who are attending primary health care centers or hospitals for other reasons, by offering clinical breast examinations. ${ }^{[21]}$
We acknowledge certain limitations of this study: Firstly, we do not have information about women who refused to participate in the study or who were not available at the time of study. If the women who were not included in the study were different from those who were interviewed in some characteristics like age, the results of the study may have been different, since age is expected to be an important determinant of awareness but it has not come out to be significant in our study. Secondly, though we had calculated a sample size of 400 , due to time constraints and logistic reasons we could only enroll 358 women. Thirdly, as this study was done in one of the blocks of a resettlement colony of south Delhi, the findings of this study could not be generalized to Delhi.

In conclusion, this study has shown that women of this resettlement colony have poor knowledge about breast cancer be it about risk factors, warning signs, or early detection procedures. Therefore it is important to create awareness and educate the community and to remove the misconceptions associated with ignorance through community based educational/awareness campaign. Early warning signs, significance of a painless lump need to be emphasized. Educating health care workers is also very important aspect. We also have to keep in mind only campaigns will not be enough, information need to be disseminated in a form which is appealing to the community.

We recommend the establishment of policy guidelines that will enhance adequate and urgent dissemination of information about breast cancer to all women.

\section{References}

1. Nandakumar A. National Cancer Registry Programme, Indian Council of Medical Research, Consolidated report of the population based cancer registries, New Delhi, India: 1990-96.

2. National Cancer Registry Programme. Ten year consolidated report of the hospital based cancer registries 1984-1993. An assessment of the burden and care of cancer patients. New Delhi: Indian Council of Medical Research; 2001

3. National Cancer Registry Programme. Consolidated report of the population based cancer registries 1990-1996. New Delhi: Indian Council of Medical Research; 2001.

4. National Cancer Registry Programme. Consolidated report of the population based cancer registries 1990-1996. Supplement: Yearwise tabulation of incident cancers and rates by site and gender. New Delhi: Indian Council of Medical Research; 2001

5. Sen U, Sankaranarayanan R, Mandal S, Ramanakumar AV, Parkin DM, Siddiqi M. Cancer patterns in eastern India: the first report of the Kolkata cancer registry. Int J Cancer 2002; 100:86-91.

6. Parkin DM, Whelan SL, Ferlay J, Raymond, L, Young J, editors. Cancer Incidence in Five Continents. Vol 7. IARC Scientific Publication 143. Lyon: International Agency for Research on Cancer; 1997.

7. Dinshaw KA, Rao DN, Ganesh B. Tata Memorial Hospital Cancer Registry Annual Report, Mumbai, India: 1999.

8. Nandakumar A, Anantha N, Venugopal TC, Sankaranarayanan R, 
Thimmasetty K, Dhar M. Survival in breast cancer: A populationbased study in Bangalore, India. Int J Cancer 1995;60:593-6.

9. Parkin DM, Pisani P, Ferlay J. Global cancer statistics 2002. CA Cancer J Clin 2005;55:74-108.

10. Seth T, Kotwal A, Thakur R, Singh P, Kochupillai V. Common cancers in India: Knowledge, attitudes and behaviors of urban slum dwellers in New Delhi. Public Health 2005:119:87-96.

11. Mishra D, Singh HP. Kuppuswamy's socioeconomic status scale: A revision. Indian J Pediatr 2003;70:273-4.

12. Parker SL, Tong T, Bolden S, Wingo PA. Cancer statistics, 1996. CA Cancer J Clin 1996;46:5-27.

13. Okobia MN, Bunker CH, Okonofua FE, Osime U. Knowledge, attitude and practice of Nigerian women towards breast cancer: A crosssectional study World J Surg Oncol 2006;21:4-11.

14. Kapoor D. Awareness of Breast Cancer in Women of India, Paper presented in UICC World Cancer Congress 2006 Bridging the Gap: Transforming Knowledge into Action on 10 July.

15. Oluwatosin OA, Oladepo O. Knowledge of breast cancer and its early detection measures among rural women in Akinyele Local Government Area, Ibadan, Nigeria. BMC Cancer 2006;6:271.

16. Tabar L, Fagerberg CJ, Gad A, Baldetorp L, Holmberg LH, Grontoft O, et al. Reduction in mortality from breast cancer after mass screening with mammography. Lancet 1985;1:829-32.

17. Gastrin G, Miller AB, To T, Aronson KJ, Wall C, Hakama M, et al. Incidence and mortality from breast cancer in the Mama Program for breast screening in Finland, 1973-1986. Cancer 1994;73:2168-74.

18. Harvey BJ, Miller AB, Baines CJ, Corey PN. Effect of breast self examination technique on the risk of death from breast cancer. CMAJ 1997; 157: 1205-12.

19. Hackshaw AK, Paul EA. Breast self examination and death from breast cancer: a Meta Analysis. Br J Cancer 2003;88: 1047-53.

20. Rao RS, Nair S, Nair NS, Kamath VG. Acceptability and effectiveness of a breast health awareness programme for rural women in India. Indian J Med Sci 2005;59:398-402.

21. WHO Screening for breast cancer. [Online] 2008. Available from: http://www.who.int/cancer/detection/breastcancer/en/. [cited 2008 Apr 15].

Source of Support: Nil, Conflict of Interest: None declared.

\section{Annexure 1: Kuppuswamy's socioeconomic status scale}

\begin{tabular}{llc} 
(A) & Education & Score \\
\hline 1. & Professional or honors & 7 \\
\hline 2. & Graduate or post graduate & 6 \\
\hline 3. & Intermediate or post high school diploma & 5 \\
\hline 4. & High school certificate & 4 \\
\hline 5. & Middle school certificate & 3 \\
\hline 6. & Primary school certificate & 2 \\
\hline 7. & Illiterate & 1 \\
\hline (B) & Occupation & Score \\
\hline 1. & Profession & 10 \\
\hline 2. & Semi-Profession & 6 \\
\hline 3. & Clerical, Shop-owner, Farmer & 5 \\
\hline 4. & Skilled worker & 4 \\
\hline 5. & Semi-skilled worker & 3 \\
\hline 6. & Unskilled worker & 2 \\
\hline 7. & Unemployed & 1
\end{tabular}

\begin{tabular}{|c|c|c|c|}
\hline (C) & $\begin{array}{l}\text { Family income per } \\
\text { month (in Rs.) } \\
\text { original }\end{array}$ & Score & $\begin{array}{l}\text { Modified } \\
\text { for } 2007\end{array}$ \\
\hline 1. & $=2000$ & 12 & $=19575$ \\
\hline 2. & 1000-1999 & 109 & 788-19574 \\
\hline 3. & $750-999$ & 6 & 7323-9787 \\
\hline 4. & $500-749$ & 4 & 4894-7322 \\
\hline 5. & $300-499$ & 3 & $2936-4893$ \\
\hline 6. & $101-299$ & 2 & $980-2935$ \\
\hline 7. & $=100$ & 1 & $=979$ \\
\hline \multicolumn{2}{|c|}{ Total score } & \multicolumn{2}{|c|}{ Socioeconomic class } \\
\hline \multicolumn{2}{|c|}{$26-29$} & \multicolumn{2}{|c|}{ Upper (I) } \\
\hline \multicolumn{2}{|c|}{$16-25$} & \multicolumn{2}{|c|}{ Upper middle (II) } \\
\hline \multicolumn{2}{|c|}{ 11-15 Middle } & \multicolumn{2}{|c|}{ Lower middle (III) } \\
\hline \multicolumn{2}{|c|}{ 5-10 Lower } & \multicolumn{2}{|c|}{ Upper lower (IV) } \\
\hline \multicolumn{2}{|c|}{$<5$} & \multicolumn{2}{|c|}{ Lower (V) } \\
\hline
\end{tabular}

